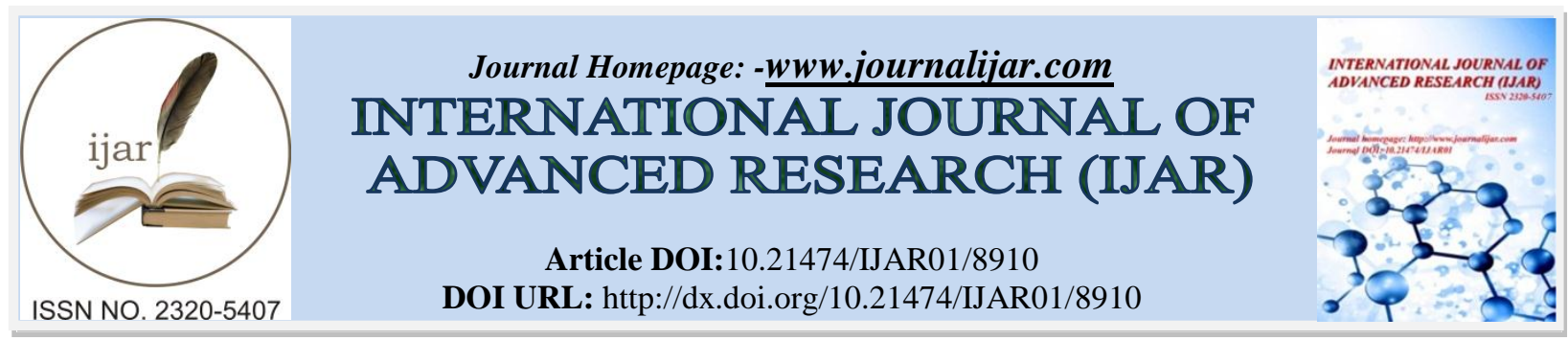

RESEARCH ARTICLE

\title{
A STUDY OF THE SOCIODEMOGRAPHIC, CLINICAL AND PATHOLOGICAL PROFILE OF LUNG CANCER. A STUDY CONDUCTED AT GOVERNMENT MEDICAL COLLEGE SRINAGAR, KASHMIR, INDIA.
}

\author{
Dar Sajad Ahmad, Dar Abdul Waheed,Shah Saqib Ahmad, Kucha Sunaullah, Akhter Haneefa, Kaneez \\ Subiya and Syed Arshad Mustafa.
}

\section{Manuscript Info}

.............................

Manuscript History

Received: 12 February 2019

Final Accepted: 14 March 2019

Published: April 2019

Key words:-

lung cancer. SOCIODEMOGRAPHIC
Abstract

Background: Lung cancer is one of the most common malignancies with high morbidity and mortality. Nonsmall cell lung cancer (NSCLC) accounts for majority of cases.

Aims: This study aims to study the clinical and pathological features of lung cancer patients treated at our institute between January 2017 and December 2018.

Materials And Methods: It is a retrospective study. 142 patients of lung cancer were retrospectively analyzed for demographic data, history of smoking, histological type, stage and treatment received.

Results: Of the 142 patients analyzed, 107 (75\%) were males and 35 (25\%) were females, with the ratio being 3:1. Most of our patients had a lesion localizing to the right side (52.8\%) than left (47.2\%). NSCLC was reported in $78.1 \%$ of our patients. Most of our patients presented at advanced stage

Conclusions: Associated risk factors, symptoms, and investigations like CT guided FNAC, BAL cytology are enormously important to diagnose lung cancer in early stage so that further mortality \& morbidity can be minimized.

Copy Right, IJAR, 2019,. All rights reserved.

\section{Introduction:-}

Lung cancer is the leading cause of death among the cancer patients worldwide. The major risk factor has been attributed to the prevalent habit of smoking tobacco. Its incidence seems to be rising in India and world over, despite several smoking cessation programs, thus indicating that several other factors contribute to its pathogenesis. The ICMR cancer registry reported 57,795 cases in 2010 , which is expected to rise by 2020 to an annual incidence of 67,000 new cases. ${ }^{[1]}$ Globocan estimate of lung cancer in India would indicate that the age-standardized incidence of lung cancer in India is 6.9/100,000 of our population. ${ }^{[2]}$ Majority of the patients present at an advanced stage of the disease, which makes management of these patients challenging. Despite advances in detection and management, the overall 5-year survival in lung cancer remains low at $15 \%$ [3].The histological subtypes of lung cancer, namely, small cell lung cancer (SCLC) and the NSCLC, exhibit varying epidemiological patterns. The clinical presentation usually depends on the location, extent of tumour. The prognosis ultimately depends on the tumour histology, staging, type of treatment used and the performance status of the patient. Limited data are available on lung cancer epidemiology in India. This study aimed to determine the profile of patients with lung cancer who were seen at a tertiary hospital.

Corresponding Author:-Dar Abdul Waheed. 


\section{Materials and Methods:-}

A retrospective analysis of all the histopathologically proven primary lung cancer patients diagnosed and treated at our center over the period of January 2017-December 2018 was carried out. Patients with secondary lung cancer, lymphoproliferative disease, malignant pleural effusion with an unknown primary were excluded from the study. A note was made of the demographical data, along with the histological subtype, side of the tumor, stage, and treatment received. Data was entered and analysed.

\section{Results:-}

A retrospective analysis of 142 patients of lung cases registered between January 2017 and December 2018 at our institute was studied. Patients ranged in age from 29 to 80 years. Majority of the patients were in the age group of 61-70 years (36.6\%). Of the 142 patients analyzed, 107 (75\%) were males and $35(25 \%)$ were females, with the ratio being 3:1.Smooking history was present in 43\%.Most of patients presented with cough(70\%),breathlessness(60\%) and haemoptysis(30\%). Most of our patients had a lesion localizing to the right side $(52.8 \%)$ than left $(47.2 \%)$. NSCLC was reported in $78.1 \%$ of our patients. Squamous cell carcinoma was the most common histological subtype (43.6\%). Adenocarcinoma was present in $31 \%$ patients, large cell in $0.02 \%$ patients and mesothelomia in $0.01 \%$. Small cell carcinoma was seen in $21.2 \%$ patients. Stage of presentation was squamous cell carcinoma $(\mathrm{I}=1.6 \%, \mathrm{II}=6.4 \%, \mathrm{III}=32.4 \%, \mathrm{IV}=59.6 \%)$, Adenocarcinoma ( $\mathrm{III}=16 \%, \mathrm{IV}=84 \%)$, Small cell carcinoma (limited stage $=19.4 \%$, Extensive stage $=80.6 \%$ ). Treatment plan was made according to the stage ofpresentation assessed by clinical examination, radiologicalfindings. Operability and type of surgery was assessed by the operating surgeon by clinical examination and examinationunder anesthesia. chemotherapy and radiotherapy was given according to protocols.

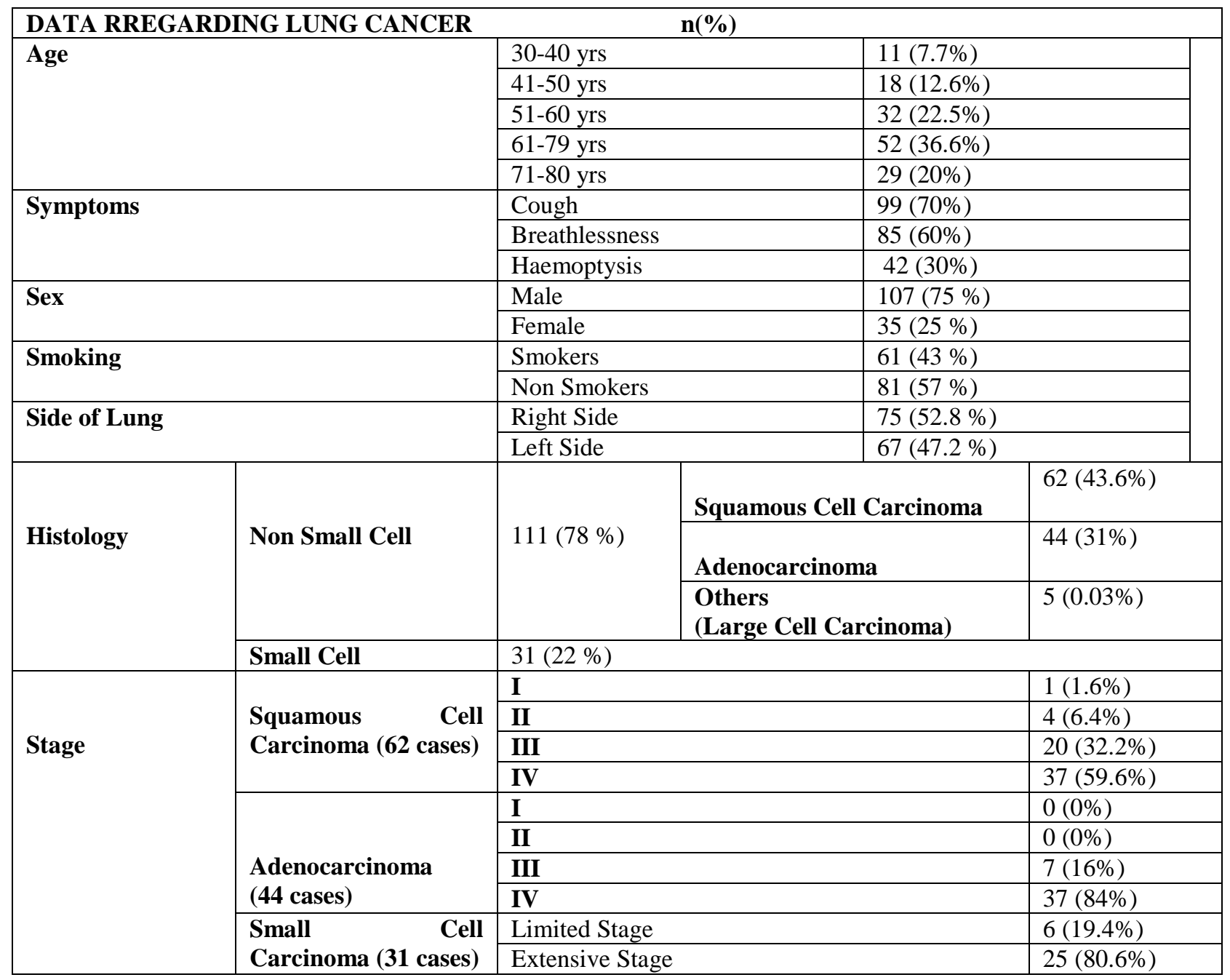




\section{Discussion:-}

The gender distribution of the patients in our study reflects the rising trend of lung cancer in women. The male to female ratio was 3:1 in this study. As per data from the ICMR Cancer Registry, July 2015, males predominate with a M: F ratio of 4.5:1. In our study there was a slight difference with male to female ratio of $3: 1$. Navin et al $2015^{[18]}$ in a recent article reported a male to female ratio of $2.7: 1 .^{[18]}$ These results show that the gap in incidence between male and female is gradually narrowing. This may be explained by the growing numbers of female smokers and the exposure of rural Indian women to biomass fuel. The growing awareness among females to seek medical advice may also have a contributory role. The median age of diagnosis in our study was 65 years, with $59 \%$ patients in the age group of 51-70 years. Noronha et al. ${ }^{[7]}$ studied 489 lung cancer patients treated over a period of an year and reported a median age of 56 years with a male to female ratio of 3.5:1. A retrospective analysis of metastatic lung cancer patients carried out at Kidwai institute found $55.6 \%$ patients in the age group of $41-60$ years. ${ }^{[8]}$

In this study, we found that $43 \%$ of patients were smokers (current or reformed). A study from Kolkata at a tertiary medical care center reported a high incidence of smoking of $81.2 \%{ }^{[9]}$ Babu et al.$^{[8]}$ found that of the 304 patients in their study, $63.5 \%$ were smokers. The cause of occurrence of lung cancer in nonsmokers remains elusive. In nonsmokers, the attributable risk factors include secondhand smoke ${ }^{[10],[11]}$ environmental exposures including asbestos, ${ }^{[12],[13]}$ arsenic, and radon; ${ }^{[14]}$ viruses like human papillomavirus; ${ }^{[15]}$ lung diseases such as idiopathic pulmonary fibrosis; ${ }^{[16]}$ and indoor air pollutants like fumes \& smoke emmited from stove. ${ }^{[17]}$

Over the past four decades, there has been a shift in the pathologic distribution of NSCLC. In the study, NSCLC (78.1\%) constituted the major histological type, with squamous cell carcinoma being most commonly found in $43.6 \%$ of patients. In the study by Noronha et al. conducted at Tata Memorial Hospital on 489 patients, they showed $92 \%$ had NSCLC histology, with squamous cell histology constituting $43.8 \%$. We found adenocarcinoma in $31 \%$ of the patients, while Noronha et al. found in $26.2 \%$ of the patients. This is in contrast to the findings reported by Babu et al. ${ }^{[8]}$ who found an equal distribution of adenocarcinoma and squamous cell carcinoma. Kumar $e t$ $a l .{ }^{[9]}$ reported squamous cell carcinoma to be the common histological type in their study of 266 patients at a tertiary center in Kolkata.

We found the right lung to be more commonly involved than the left and so was seen by Mohan et al. $(52.3 \%)^{[18]}$ and Kumar et al. $(65.79 \%)$ in their studies.

In our study majority of patients were presented at advanced stage. $70.5 \%$ patients were diagnosed with stage IV disease, $18.9 \%$ patients with stage III, $6.6 \%$ with stage II, $3 \%$ patients with stage I. Chandra S et al ${ }^{[16]}$, conducted study, found $90.2 \%$ of NSCLC patients had stage IIIB or IV disease at the time of diagnosis. In a study by Bhattacharyya Sujit Kumar et al ${ }^{[17\}}$, about $71.8 \%$ patients diagnosed in the later stage of diseases were either in stage IIIB or IV. However extensive investigation for staging of lung cancer was not possible due to economic constrains and unavailability of certain diagnostic modalities, like PET scan, mediastinoscopy, thoracoscopy, and others in our institution. CT scan of other organs and bone scan was done in symptomatic patients only. Hence accurate staging was not possible and the actual number of patients with nonresectable carcinoma stage III B/IV disease may actually be under reported in this study.

\section{Conclusions:-}

Squamous cell carcinoma with right upper lobe of lung was prevalent among cases. Tobacco smoking was found to be the major etiological factor. Associated risk factors, symptoms, and investigations like CT guided FNAC, BAL cytology are enormously important to diagnose lung cancer in early stage so that further mortality \& morbidity can be minimized. Hence, awareness in the society about the deleterious effect of tobacco smoking is warranted to reduce the incidence.

\section{References:-}

1. Takiar R, Nadayil D, Nandakumar A. Projections of number of cancer cases in India (2010-2020) by cancer groups. Asian Pac J Cancer Prev 2010;11:1045-9.

2. Available from: http://www.globocan.iarc.fr/Pages/fact_sheets_cancer.aspx. [Last accessed on 2016 Feb 20].

3. Jemal A, Siegel R, Ward E, Hao Y, Xu J, Murray T, et al. Cancer statistics, 2008. CA Cancer J Clin 2008;58:71-96. 
4. Noronha V, Dikshit R, Raut N, Joshi A, Pramesh CS, George K, et al. Epidemiology of lung cancer in India: Focus on the differences between non-smokers and smokers: A single-centre experience. Indian $\mathrm{J}$ Cancer 2012;49:74-81.

5. Babu G, Lakshmaiah KC, Kamath M, Lokanath D. Metastatic lung cancer at a tertiary cancer centre in South India. J Thorac Oncol 2017;12 (Suppl):S484-S5.

6. Kumar BS, Abhijit M, Debasis D, Abinash A, Ghoshal AG, Kumar DS, et al. Clinico-pathological profile of lung cancer in a tertiary medical centre in India: Analysis of 266 cases. J Dent Oral Hygiene 2011;3:30-3.

7. Brennan P, Buffler PA, Reynolds P, Wu AH, Wichmann HE, Agudo A, et al. Secondhand smoke exposure in adulthood and risk of lung cancer among never smokers: A pooled analysis of two large studies. Int $\mathrm{J}$ Cancer 2004;109:125-31.

8. Vineis P, Airoldi L, Veglia F, Olgiati L, Pastorelli R, Autrup H, et al. Environmental tobacco smoke and risk of respiratory cancer and chronic obstructive pulmonary disease in former smokers and never smokers in the EPIC prospective study. BMJ 2005;330:277.

9. van Loon AJ, Kant IJ, Swaen GM, Goldbohm RA, Kremer AM, van den Brandt PA, et al. Occupational exposure to carcinogens and risk of lung cancer: Results from the Netherlands cohort study. Occup Environ Med 1997;54:817-24.

10. Chen CL, Hsu LI, Chiou HY, Hsueh YM, Chen SY, Wu MM, et al. Ingested arsenic, cigarette smoking, and lung cancer risk: A follow-up study in arseniasis-endemic areas in Taiwan. JAMA 2004;292:2984-90.

11. Darby S, Hill D, Auvinen A, Barros-Dios JM, Baysson H, Bochicchio F, et al. Radon in homes and risk of lung cancer: Collaborative analysis of individual data from 13 European case-control studies. BMJ 2005;330:223.

12. Ciotti M, Giuliani L, Ambrogi V, Ronci C, Benedetto A, Mineo TC, et al. Detection and expression of human papillomavirus oncogenes in non-small cell lung cancer. Oncol Rep 2006;16:183-9.

13. Hubbard R, Venn A, Lewis S, Britton J. Lung cancer and cryptogenic fibrosing alveolitis. A population-based cohort study. Am J Respir Crit Care Med 2000;161:5-8.

14. Yu IT, Chiu YL, Au JS, Wong TW, Tang JL. Dose-response relationship between cooking fumes exposures and lung cancer among Chinese nonsmoking women. Cancer Res 2006;66:4961-7.

15. Mohan A, Latifi AN, Guleria R. Increasing incidence of adenocarcinoma lung in India: Following the global trend? Indian J Cancer 2016;53:92-5.

16. Chandra S, Mohan A, Guleria R, Singh V, Yadav P. Delays during the diagnostic evaluation and treatment of lung cancer. Asian Pac J Cancer Prev. 2009 JulSep;10(3):453-6.

17. 17. Bhattacharyya Sujit Kumar, Mandal Abhijit, Deoghuria Debasis, Agarwala Abinash, Aloke Gopal Ghoshal and Dey Subir Kumar. Clinico-pathological profile of lung cancer in a tertiary medical centre in India: Analysis of 266 cases Journal of Dentistry and Oral Hygiene Vol. 3(3), pp. 30-33, March 2011.

18. Navin P, Balbir M, Nirmalchand K. Clinico pathological Profile of Patients with Lung Cancer Visiting Chest and TB Hospital Amritsar. Sch. J. App. Med. Sci. 2015;3(2D):802-9. 